\title{
Izquierda y derecha en política
}

- Ángel Rodriguez Kouth*

Los conceptos de izquierda y derecha — nacidos con la Revolución Francesa- como analizadores de la posición política, luego de dos siglos han caído en una franca confusión de sus referentes. Tanto la izquierda tradicional, que pretende moderar su discurso para ser aceptable por los sectores medios y altos del electorado, como la derecha histórica que ha lavado sus textos en una suerte de populismo para lograr adeptos entre el proletariado. La contemporaneidad puede observar de ¿qué manera se están traslapando los discursos y se hace muy difícil poder discernir quićn está a la diestra de quién, a la par que la clásica sinicsıra se ha mimctizado con los discursos de la derecha.

\section{La confusion de las ideas en la miseria de las ideas}

En una rápida y breve historia de la participación política, es posible señalar quc, en el Antiguo Régimen, el número de personas que procuraban ocupar cl poder político o, al menos orientarlo, cstaba limitado a los círculos palacicgos. Desde la Revolución Francesa no cesa de aumentar el número de personas que pretenden designar a los gobernantes y determinar lo que sea el bien común. El proceso de crecimiento culmina en el primer cuarto del siglo XX con el permanente acceso de las masas a la política. Se trató de una participación alterada por las manipulaciones de la opinión y por las técnicas representativas, muchas veces engañadoras; pero, estafadas o no, las sociedades se politizaron, es decir, se fragmentaron en posiciones colectivas ante la cosa pública. Incluso, los más alejados del ágora, en su intimidad, toman partido. En la actualidad se observa una paradoja, mientras la inmensa masa de la población considera a la participación política como una perversión, ocurre un hecho paradojalmente curioso. Ante 
posibles elecciones abiertas o, con el "sistema de lemas", presentan su candidatura hasta uno de cada 30 ciudadanos en condiciones de inscribirse.

Recordando una cita de C. Marx (1847), que dice: “... que mientras en la vida vulgar y corriente todo tendero sabe perfectamente distinguir entre lo que alguien dice ser y lo que realmente es, nuestra historiografía no ha logrado todavia penetrar en un conocimiento tan trivial como éste. Cree a cada época por su palabra, por lo que ella dice acerca de si misma y lo que se figura ser". En la actualidad, no sólo la historiografía cae en ese dislate de ingenuidad intelectual, sino que también lo hacen los pueblos y los politólogos.

Para estimular adhesiones, los partidos afirman valores propios, a la vez que se los niegan a sus adversarios. Los respectivos portavoces y clientelas multiplican las consignas de los líderes, tanto estas sean críticas o apologéticas. En el último tercio del siglo XX fue difícil encontrar un ciudadano occidental que no contemple su política nacional como un enfrentamiento de valores y contravalores, o sea, en términos morales de buenos y malos, una relación de antagonismo y agonismo. Ese talante tan generalizado, y no carente de fundamento, afecta también a los politólogos, que tienden a explicar la dicotomía derecha e izquierda con tácitos o expresos juicios de valor, por ejemplo, el comunismo es terror, el capitalismo es explotación. Asimismo, tanto para los definidos como de "derechas", como para los del anodino "centro", las izquierdas son materialistas y ellos son idealistas. Lo mismo ocurre a la inversa. Y ambos tienen razón, la izquierda es materialista por definición, aunque no por ello sus planteos no estén rebalsados de utopías. De la misma manera, la derecha puede ser definida como idealista a partir de su asociación con poderes sobrenaturales, aunque a nadie en su sano juicio le costaría reconocer que el pragmatismo con que se rodea no es una forma de expresión materialista en el orden de la generación de bienes financieros y cconómicos. Es decir, derechas e izquierdas no tienen la exclusión de los atributos "idealista" y "materialista", en tanto y cuanto cualquiera de las dos expresiones políticas hacen uso -y abuso- de tales características y, además, todo depende de cómo sean definidas previamente, ya que cada uno de esos atributos pueden ser leídos de diferente manera por distintos filósofos políticos.

A fin de poder enfocar el tema desde una perspectiva no ya neutral. sino solo con pretensión empírica, hay que proceder a una "metanoia" intelectual, a una renuncia a los sentimientos habituales y a los prejuicios arraigados a fin de interpretar los datos y elaborar una tipología política estrictamente racional. Hay, en suma, que situarse en un nivel cero de emotividad y partidismo. Si no se logra el giro mental de considerarse metódicamente sin compromiso, será imposible abordar la delimitación de la derecha y de la izquierda políticas sin caer en alguna forma de loa o de diatriba. ¿Cómo caracterizaría hoy a la derecha y a la irquierda un puro logos desencarnado, científico? Esa es la ardua meta intelcctual. 
El siglo XXI encuentra al mundo en un vacío de ideas, y no como consecuencia de las predicciones de Fukuyama (1990). Es que pareciera que las ideas se han convertido en miserables. Hechos y no palabras, pareciera ser la consigna del momento. No se sabe muy bien si lo que impera es la ideología de la miseria (Proudhon, 1846), o la miseria de las ideologías (Marx, 1847).

\section{Origen ocasional}

La derecha y la izquierda, generalmente referidas a la orientación de la mano, son términos anatómicos de gran precisión, puesto que el punto de referencia, que es el cuerpo, permanece en una posición determinada. Cuando afirmamos de alguien que es diestro o zurdo no hay duda alguna acerca del significado. Cuando la acepción es trasladada a otros ámbitos significativos, la derecha y la izquierda pierden su valor absoluto, se convierten en nociones relativas al observador. Así se produce la clásica tergiversación del viandante que pregunta por una dirección, y su interlocutor frontal califica como derecha lo que para el demandante es todo lo contrario, porque es un lugar situado a su izquierda. La geografía desecha una terminología tan confusa y la sustituye por la más precisa de los puntos cardinales.

La distinción entre izquierdas y derechas se aplicó, por primera vez a la política, en la Francia revolucionaria. La Asamblea Constituyente, inició sus trabajos en 1792. Los diputados se hallaban divididos en dos grupos enfrentados: el de la Gironda, que se situó a la derecha del Presidente, y el de la Montaña, que se situó a la izquierda. En el centro tomó asiento una masa indiferenciada a la que se designó como el Llano —o la Marisma-. Los girondinos deseaban restaurar la legalidad y el orden monárquico, mientras que La Montaña propugnaba un estado revolucionario, el cual, después de anular a los girondinos, desembocaría en lo que se conoció - lamentablemente, aunque con justicia - como el Terror. Así se produjo una identificación de la izquierda con la radicalización revolucionaria que, al grito de "Libertad, Igualdad y Fraternidad", desencadenaría una etapa de utopías y ferocidad que sólo lograría detener el golpe de Estado de Bonaparte. Los implacables Robespierre, Danton y Marat fueron los caudillos y los delinidores del primer partido político francés que se situó a la izquierda.

\section{Significacion equívoca}

Dos siglos transcurrieron desde la Convención hasta hoy y, sin embargo, ni la derecha ni la izquierda política logran dotarse de contenidos pragmáticos continuos y relativamente estables. Por ejemplo, los liberales argentinos eran la izquierda en tiempos de Organización Nacional, y son la derecha en tiempos del Inenemismo. En Europa, la derecha era nacionalista hasta la II Guerra Mundial; pero poco después creó la Unión Europea, máximo exponente contemporáneo de la superación del Estado nacional. Objetivo éste último auspiciado desde el 
siglo XIX por el internacionalismo socialista, aunque llegado el momento no participó de los fastos de creación de tal organización transnacional.

La historia política muestra que los programas de la derecha y de la izquierda evolucionan de manera rotunda y, a veces, errática. Quizás el caso más elocuente sea la actual adhesión a la economía de mercado por parte de los contemporáneos comunismos reciclados, antes prototipos del intervencionismo estatal absoluto hasta llegar a convertirse en un capitalismo de Estado en la ex Unión Soviética.

Una evolución más lenta, pero paralela, fue la de las socialdemocracias desde la escisión de la Internacional Socialista. Sin salir de los límites de un país como Gran Bretaña, la izquierda laborista del estatista Premier Attlee, apenas sería reconocible en el actual gobierno del privatista Blair: el socialismo de éste hubiera sido considerado derechista hace sólo medio siglo. El peronismo, en Argentina, fue estatista - aunque derechista - de la mano de Perón, aunque en la actualidad alcanzó la cumbre — con la conducción del menemismo- de las privatizaciones. Es evidente, entonces, si abundáramos en más ejemplos obvios, que los cambios copernicanos de programas políticos no conocen fronteras. La derecha y la izquierda políticas carecen de contenido estable a escala universal y también nacional; son tan relativas como en geometría. Otro ejemplo. Durante la Cumbre de la Internacional Socialista realizada en Buenos Aires — junio de 1999- se tuvo oportunidad de asistir, atónitamente, a la definición, por parte de variados líderes socialdemócratas, de la "tercera vía" propuesta tanto por el laborismo británico y los socialismos francés y alemán, como que "... apoyamos una economia de mercado, no una sociedad de mercado", es decir, una disociación economía y sociedad, a las cuales, M. Weber (1944) no las veía como separadas - difícil de comprender más allá de la retórica fácil de los discursos huecos. Y, más difícil aún, proviniendo de dirigentes de la socialdemocracia internacional, que si bien nunca se han mostrado como revolucionarios plenos, al menos han sido tibiamente progresistas.

Los dinamismos, a veces pendulares, de los programas partidistas impiden una caracterización general de la derecha y la izquierda; su descripción ha de ser coyuntural para un lugar y un tiempo. Tal historicismo inutiliza a los términos como permanentes categorías politológicas.

En suma, la distinción entre derechas e izquierdas políticas es más histórica que lógica y, consecuentemente, tiene un valor nominal, un contenido cambiantc, una significación ocasional, y no es una terminología hermenéutica invariable para exponer la historia de la teoría y de la praxis políticas, ni siquiera en la cdad contemporánea.

\section{El complejo de inferioridad}

En numerosas lenguas el vocablo que designa a la izquierda anatómica ha padecido connotaciones negativas. Hay culturas donde la mano izquierda está 
reservada para menesteres indignos. La condición de zurdo ha sido considerada como una anomalía y una presunción axiológicamente desfavorable. El término latino siniestro adquiere en la prosa contemporánea una significación moralmente negativa, que es la preferentemente heredada por algunas lenguas romances y entre ellas, por el español, donde prevalece la acepción de perverso, oculto, para lo siniestro (Falcón, 1997); quizás sea esa la razón de que se fuera imponiendo el eufemismo "izquierda".

A pesar de tan adversa tradición semántica, los posthegelianos reivindicaron su condición de izquierdistas. Y en Francia, los herederos de la Revolución procedieron a una progresiva dignificación del izquierdismo: "la gauche divine", tarea a la que se incorporaron diferentes socialismos, incluido el marxista. En la guerra de las palabras y de las ideologías, los autodenominados "progresistas" descalifican a los tachados de derechistas como reaccionarios, defensores de privilegios inicuos, y adversarios de la justicia social. Llegados a este extremo, cercano a lo satánico, algunos acusados empezaron a rechazar la condición de derechistas para adoptar otras denominaciones - aún no totalmente desprestigiadas - por la ofensiva retórica de sus adversarios: conservadores, populistas, democristianos, centristas, etc.

Así se ha llegado a la situación actual, que es la desaparición de la denominación "derecha" en la nomenclatura de los partidos políticos. Pero la cuestión no es sólo nominal: el complejo de inferioridad moral que los socialismos consiguieron inocular a sus oponentes llevó a estos a posiciones izquierdistas en lo que consideraron marginal al modelo de libre mercado, como en el plano de la cultura exquisita.

De tal forma se ha arribado a la paradójica situación actual: hay centro, izquierda y extrema izquierda; pero nadie se dice de derecha. Esto es una especic de hemiplejía política. Y, además, aparece la paranoica huida de los liberales hacia un supuesto centro para escapar de la proscripción verbal dictada desde la izquierda. Una primera aproximación a la definición de la derecha sería la posición política en la que nadie quiere ser situado. Claro que si esta fase dialéctica concluyera con la total desaparición de la derecha nominal, empezaría otra similar contra el centrismo como derecha vergonzante o encubierta. Es la humillación de cambios de nombre, hipocresías, enmascaramientos, concesiones y entregas a que se condenan quienes padecen esto que se puede definir como complcjo de inferioridad política de identificación.

Es posible ilustrar esto en la Argentina de 1999, dónde con un gobierno - menemismo- extremadamente liberal en lo económico y con un absoluto corrimiento del Estado de su obligaciones legales (Cfr. Rodríguez Kauth, Del Estado...), no exista organización política alguna que se defina como de derecha. $\mathrm{Ni}$ aun la del propio Domingo Cavallo, quien fue el numen de las privatizaciones durante su gestión como funcionario del menemismo. 


\section{Una lectura comparativa}

A pesar del escepticismo de muchos politólogos, tanto los periodistas como los políticos śguen utilizando la vieja distinción de izquierdas y derechas. Resulta difícil pensar que todos manejen un comodín equívoco, en todo caso, lo que utilizan es una reducción simplista; ya que se trata de términos relativos, y por lo tanto, históricos. Tanto las derechas como las izquierdas no han mantenido un contenido unívoco y estable. Ha sido superada la distinción entre las derechas e izquierdas de 1850, de 1900 o de 1950; pero, con significado distinto, subsisten en la actualidad. Periódicamente aparecen ensayos para delimitar los campos e -incluso- para salvar los contenidos de algún tiempo pasado. Asimismo, Del Río (1999) considera que en las dos últimas décadas la distinción entre derechas e izquierdas políticas se ha visto complicada en lo que se refiere a políticas gubernamentales. La izquierda como campo político, social e ideológico está más viva en Francia que en España o Alemania.

A continuación, intentaré desarrollar una suerte de diferenciación de ambos espectros y cómo los mismos terminan por confundirse.

a) Desde una caracterización racional, la izquierda sería un paradigma racionalista; mientras que la derecha se ubicaría del margen pragmático. Esto se apoya en que, desde Marx, la producción teórica de la izquierda ha sido mucho más voluminosa y compartida por mayor número de intelectuales que la de la derecha, a la cual se la puede considerar pobre de contenidos ideacionales. Pero, una mayor masa de bibliografía y de académicos no implica necesariamente mayor densidad racional.

Las derechas, en sus diversas versiones, siempre han contado con doctrinarios básicamente racionalizadores. Un ejemplo de esto último ha sido A. Smith (1784).

Se suele argumentar en contra de la superioridad racional de la izquierda que, durante la épora de dominación comunista en Moscú, la producción intelectual surgida de los espacios geográficos dominados por aquellos, fue simplemente una retahíla de obsecuencias. Sin embargo, esto carece de valor cuando se piensa en autores marxistas críticos que llevaron adelante una prolífica obra de esclarecimiento político y social no dogmático. Caso semejante ocurre con los panegiristas de la derecha durante sus "reinados" (p. ej.: K. Schmitt en Alemania y B. Croce en Italia).

b) También se ha sostenido lo contrario, o sea, que la izquierda se ha desarrollado sobre la emotividad, y la derecha sobre la racionalidad. Esta interpretación se apoya en el hecho de que las políticas igualitarias del socialismo arraigan en la envidia y hasta en el resentimiento, mientras que - sostiene la derecha- la meritocracia se fundamenta en algo tan razonable como la jerarquización de valores. Pero esta exégesis explica únicamente una etapa, no todas. El liberalismo, que fue la izquierda a mediados del siglo XIX, era una construcción 
tcórica, que no se fundaba en demagogias emotivas; en cambio, aquélla derecha conlicsional de la época se sostenía en sentimientos religiosos.

c) Una variante de esta distinción formal, que ya deja de ser tal, pues se presenta cargada de contenidos, es la que identifica a la derecha con fideísmo y confesionalismo, y a la izquierda con secularismo y laicismo. Según esta clave, Aristóteles, que no creía en ninguna religión, sería un doctrinario izquierdista. Pcro es que, además, siempre ha existido una derecha agnóstica: en Francia, la que arranca del positivismo comtiano y pasa por Maurras; en España la de tantos moderados como Mon, Giner, Costa u Ortega; en Argentina, Leopoldo Lugones scría el paradigma de tal fenómeno. En cambio, existe una izquierda mitológica como la jacobina que implanta el culto a la diosa razón, entronizada solemnemente en la catedral de París, o como el marxismo que se convierte en nueva fe con su libro revelado, su profeta, sus fanáticos, sus autores prohibidos, sus iconos, sus misioneros, sus anatemas, sus autos de fe e incluso su cuerpo incorrupto. Las guerras de religión, que subsisten, ya no en la India o Libano, sino en los inmediatos Balcanes ¿serían sólo entre derechistas?. Es absurdo afirmarlo. La apclación política a lo divino se remonta a los orígenes de la Humanidad y, la cxpcriencia, demuestra que hay derechistas e izquierdistas incrédulos y creyenIcs. Que una parte de la izquierda política contemporánea fuera laica no permite la gencralización, ya que, por ejemplo, Latinoamérica observa absorta los coqueteos de la izquierda con la llamada teología de la liberación, como una cstraIcgia oportunista de recuperar espacios perdidos entre las masas (Ferrater Mora, 1971; Rodríguez Kauth, 1993).

d) Otra variante de la distinción formal es identificar a la izquierda con la utopía y a la derecha con el realismo. Si por utopía sc entiende lo absolutamente imposible, la connotación será negativa y descalificadora, puesto que la política es cl arte de lo realizable. Pero si por utópico se entiende una orientación ideal al que efectivamente cabe aproximarse, los hechos no confirman que las derechas políticas hayan carecido de ideales, más bien al contrario, aunque los mismos no scan - para mí- valiosos. Por ejemplo, las derechas confesionales, se han propuesto metas morales cuyo término, por definición, es un bien sumo al que cabe acercarse sin rebasarlo jamás. En todo objetivo ético hay un extremo que funciona como un límite, es decir, como un punto que está siempre más allá cle todos los de la serie infinita a la que pertenece. Si bien es cierto, los idealismos no son monopolio de la izquierda ni de la derecha política, sin embargo, se puede afirmar que la izquierda levanta ideales altruistas y de solidaridad que no se cncuentran en los idearios de la derecha, por la sencilla razón de que ésta es cgoísta y eminentemente pragmática.

\section{Una lectura desde la moral}

La práctica usual de caracterización de la derecha y la izquierda consiste en adscribirles — como es obvio-valores diferentes. Resulta casi imposible alejar- 
se de esta recurrencia judicativa a ser considerado mejor que el otro, ya que es consubstancial al quehacer político. Pero tal metodología axiológica no es neutral, debido a que los valores se ordenan jerárquicamente, e inclinarse a favor de unos suele implicar la afirmación de una superioridad o inferioridad con respecto a los de la orientación contraria. Además, cada valor enfrenta a su opuesto y, adjudicar uno positivo sugiere carencias en quien no lo posee. En fin, los valores afectados en este caso son fundamentalmente morales y les es consubstancial la gradación que va desde lo óptimo hasta lo pésimo pasando por lo mejor, lo bueno, lo mediocre, lo malo y lo peor. Suele ocurrir que caracterizar a las corrientes políticas según sus contenidos axiológicos es abandonar la neutralidad para incidir en la diatriba o la loa, ya tácitas, ya expresas.

a) Es un lugar común que el valor predominante de la izquierda sería la igualdad, mientras que en la derecha primaría la jerarquía. Esto es una traslapación de posturas que contraponen otro par de valores, el de la libertad y el del orden.

La igualdad de los individuos humanos no es un ideal, ni siquiera una utopía, cs una falsedad puesto que no hay dos hombres idénticos ni biológica, ni intelectual, ni moral, ni lécnicamente. Sólo es factible la igualdad de oportunidades; pero este objetivo, que tiende a superar discriminaciones injustificadas y ocasionales, es un lugar común de los programas partidarios. La pretensión izquierdisla de encarnar la demanda de igualdad de oportunidades es tan carente de fundamento objetivo como la de monopolizar el calificativo de "progresista", según la antigua retórica soviética. En una arenga o en un artículo partidista tales manipulaciones del lenguaje suelen ser consideradas como corruptelas tolerables; pero a nivel tcórico, no. La igualdad de oportunidades no la niega nadie. Otra cosa es la dificultad de imponerla a causa de la intrínseca historicidad del individuo humano y la imposibilidad de anular la temporalidad y espacialidad en que se encuentra todo lo matcrialmente concreto.

Por otro lado, la igualdad de oportunidades no se produce espontáneamente, ha de ser impuesta, y tal decisión requiere un poder, o sea, jerarquía. No sólo no hay contraposición efectiva entre libertad y jerarquía, sino que ésta es condición de aquélla. Y en el fondo aparece la inevitable autoapología. Unos valores son cstimados como superiores a otros, y situarse en tal campo suele equivaler a elogio y crílica. El sometimiento a una jerarquía no es inicialmente grato, mientras que la afïrmación de la igualdad entraña cierto narcisismo.

Y los datos históricos no corroboran esta interpretación. La primera izquierda propiamente dicha, la de la revolución francesa, no cesó de atribuirse la búsqueda de la igualdad; pero dio lugar a la dictadura de un grupo de los privilcgiados jacobinos. Y el presunto salvador de la revolución que se devoraba a sí misma. Napoleón, creó la suntuosa aristocracia familiar y militar del Imperio en la Francia metropolitana y en las naciones vencidas: reyes, príncipes, grandes duques y títulos innumerables. Un abismo de desigualdad separaba al pueblo de 
las nuevas aristocracias revolucionarias. Similar fue el curso de la revolución soviética: al grito de igualdad se constituyeron, en Rusia y en los países satélites, la "nueva clase" y la "nomenklatura", tan alejadas de las bases como la nobleza zarista. $Y$ al liquidarse la Unión Soviética, esa clase privilegiada ha sobrevivido, aún más enriquecida, gracias al corrupto proceso de privatización de empresas públicas. La potencia que Lenin condenó por explotadora de los trabajadores, los Estados Unidos, ¿no ha engendrado más desigualdad real que la que existía? Una cosa es lo que se predica y otra lo que efectivamente se hace. Clasiticar a los movimientos políticos por sus declaraciones programáticas o sus consignas propagandísticas es un ingenuo criterio nominal, no sociológico ni político.

b) Transportar la oposición derecha-izquierda a los valores de libertad-igualdad tampoco resulta esclarecedor porque ni los datos históricos, ni el análisis teórico confirman tal contraste. La derecha contrarrevolucionaria del siglo XIX era más bien absolutista, mientras que la izquierda era libertaria y enarbolaba, sobre todo, el primer término de la famosa trilogía de 1789.

Tampoco el análisis conceptual confirma el supuesto contraste, porque libertad e igualdad no se oponen: existen liberales igualitarios y no igualitarios, del mismo modo que hay demócratas igualitarios y autoritarios (ejemplo de estos últimos fue el socialismo real). La igualdad es un valor relativo que supone una previa estratificación, mientras que la libertad es un valor absoluto referible a cualquier nivel social; no se oponen, ni excluyen, sino que son compatibles y complementarios.

c) Cruzando el plano ético con el histórico, se ha dicho que la derecha y la izquierda representarían dos actitudes ante la justicia. Aquélla pretendería conservar lo justo ya obtenido, mientras que ésta siempre trataría de avanzar hacia cotas más altas de justicia. Esta interpretación no está respaldada por la experiencia. La izquierda de la revolución francesa empezó aniquilando el orden establecido, lo que desembocó no solamente en anarquía sino - lo que es peoren injusticias. No fue diferente la revolución soviética. Posiblemente, la meta era más justicia; pero la realidad fue la contraria.

d) Exagerando el panegírico, se ha afirmado que la derecha es el egoísmo interesado y la izquierda el altruismo filantrópico. Pero tal interpretación no es una caracterización, sino una dogmática descalificacion de la derecha, ya que el altruismo es socialmente el bien, mientras que el egoísmo es el mal. Un examen sereno de la historia contemporánea de Europa y Latinoamérica no justifica tal demonización partidista. El más elemental balance de nuestro pasado ¿dónde situaría a un supuesto o real Imperio del mal? ¿En el más o menos derechista Occidente o en el Este, suprema encarnación del izquierdismo? Creo que sin apasionamientos se lo puede ubicar en ambos lados geográficos, es decir, el mal no es patrimonio de unos, como tampoco lo es el bien. 
c) Son falsos los dilemas entre orden y justicia, entre jerarquía y libertad, entre libertad e igualdad, entre conformismo e inconformismo, entre egoísmo y altruismo, coma lo son todos los análogos entre tradición y ciencia, entre conscrvación y progreso, entre individualismo y solidarismo, entre nacionalismo y cosmopolitismo. Esas dicotomías de grandes polisemias no son mutuamente excluyentes, ni coinciden con las derechas y las izquierdas históricas. Más, se apoyan en peticiones de principios morales donde un término es el bueno y el otro el malo. Dos siglos de tal dialéctica han creado conflictos sociales; pero escasa luz lógica. Quizás los demagogos y sus escribas continúen con tales manipulaciones; pero el estudioso debe repudiarlas por ideológicas en el peor sentido del vocablo, es decir, por no cientílicas. Es preciso abandonar la pretensión moralista, atrayente para el activista de barricada y buscar una conceptualización, una distinción objetiva y empírica a la vez, compatible con el dinamismo de una época ya que no histórico universal.

\section{Izquierdas y derechas ante el estado}

La definición aclual y concreta del Estado viene dada por un ordenamiento jurídico. Sus actores son tanto los funcionarios como la inmensa masa de ciudadanos.

Desde sus incicrtos antecedentes, el Estado no ha cesado de complicarse y crecer. En cl siglo XX, algunos Estados europeos han llegado a administrar más de la mitad del producto bruto interno. El Estado, identificado por Hobbes ( 1651 ) como Leviatán y lucgo divinizado por Hegel, es una realidad colosal.

El Estado es una ligura inseparable del Derecho, y éste requiere coacción. El impcrativo y la consiguiente constricción de las libertades individuales es el aspecto negativo del aparato estatal: el orden que impone va acompañado de violencia. Legítima o ilegítima, el Estado entraña necesariamente fuerıa. Pcro tal coerción resulta — para la mayoría - menos rechazable que el caos y la anarquía, que es la que impone físicamente el más fuerte. La convivencia sin Estado es un idcal lcjano, a la par que un imposible para la actual forma social de vida que sc han dado los humanos. Es irracional pretender la supresión de las formas políticas de coacción, especialmente de la más evolucionada, que es el Estado. La presencia del Estado es un mal menor que su ausencia, y la razón aconseja accptarlo con sus reglamentaciones, sus cárceles y sus impuestos, aunque esto no signifique que se intensifique la lucha por reducir su presencia de abusos autoritarios. Los cstatistas lienden a presentar como anarquistas a quienes no apoyan la constante hipertrofia del Estado y el progresivo estrechamiento de las áreas de autodeterminación individual. Es un recurso reduccionista y tan rancio como la invención del maniqueísmo.

No es sólo la acuciante alternativa entre vivir en relativa paz o la constante amenaza de rapiña y aún de muerte; es que la prótesis cultural que nos capacita 
y perfecciona es, en gran parte, fomentada y conservada por el Estado. Ser más o menos humano depende en gran medida del Estado. Hay una correlación entre la calidad estatal y la ciudadanía. La cuestión estriba en el tamaño del Estado.

En la actualidad, las tensiones de las sociedades avanzadas no se producen cntre monárquicos y republicanos, confesionales y laicos, presidencialistas y parlamentaristas, sufragistas calificados o universales. Sea cual fuere la real sustancia imperativa de los derechos humanos, nadie discute su formal proclamación y la necesidad de su protección. Tampoco se niega la igualdad de oportunidades o la protección al desvalido. Lo que ahora divide y caracteriza a las izquierdas y a las derechas no son dos valores aparentemente contrapuestos como la libertad y la autoridad, ni siquiera intereses de clase enfrentados como los de la burguesía y el proletariado. La confrontación se produce a lo largo de una dimensión única: la estatalidad y es, por tanto, cuantitativa y, en sí, axiológicamente neutra: más o menos Estado. ¿Qué funciones y en qué medida se pueden privatizar?. Es el debate político por excelencia en las sociedades desarrolladas.

¿Ahorro público o privado?, ¿qué tipo y proporción de empresas estatales?, ¿qué áreas de orden público pueden ser asumidas por entidades particulares?, ¿qué pleitos se substanciarán en tribunales o en despachos de arbitraje?, ¿seguridad social de capitalización personal o de reparto colectivo?, ¿enseñanza estatal o privada? En suma ¿qué proporción de la renta nacional será administrada por funcionarios públicos' La izquierda, hasta inicios de la última década del siglo, ha propugnado más Estado, la derecha - en cambio- menos Estado. Esta es la aclual polémica objetiva, mensurable y comparable del dualismo terminológico cn la política contemporánea.

La preferencia por el tamaño del Estado responde a una teoría que, en primer lugar, puede tener fundamentación empírica. ¿Quién controla más eficazmente al gestor?, ¿el empleado, el propietario, o el burócrata de la administración pública? Al respecto, la experiencia es ambigua y otorga razones a unos y otros demandantes.

Pcro la preferencia por más o menos Estado tiene también una fundamentación pragmática con cierta connotación moral, recibida del socialismo en sus dilerentes versiones, sobre todo, del marxismo. Se trata, inicialmente, de la cuestión de la plusvalía, ya que la propiedad pública haría que se revirtiese sobre toda la sociedad y no sólo sobre el propietario de los bicnes de producción.

Es tambićn la cuestión de la libertad: cuanto mayor la dimensión del Estado existen menos márgenes individuales de autodeterminación. La creciente fiscalidad cs una forma muy severa de opresión porque priva al ciudadano de fracciones de su tiempo, a veces, de más de la mitad; es una variante del trabajo forzado, una csclavitud parcial que suele aplicarse progresivamente, en proporción a la capacidad y laboriosidad de las personas. Cuanto más fracasado e improductivo sca el ciudadano. menos le será confíscado por el Estado que -incluso- le 
obsequiará con fracciones de lo decomisado a los otros. De ahí que los ciudadanos sean más estatistas cuanto más minusválidos. Es cierto que en la coyuntura actual la derequa postula más libertad concreta; pero, $i$ acaso sólo para ciertas personas privilegiadas por el previo reparto de la propiedad? Es el debate sobre las libertades formales y las reales suscitado por el socialismo de cátedra. Para equiparar las dosis individuales de libertad hace falta la violencia redistributiva del Estado, afirman los intervencionistas. Tal acción estatal, sostienen los liberales económicos, reduce el monto total de libertad en la sociedad. La experiencia contemporánea ha dado la razón a estos; pero subsiste la radical correlación: no hay libertad sin algunos recortes a la misma. Se trata de una gradación prudente.

En este debate, durante la primera mitad del siglo XX, la corriente hegemónica fue la izquierdista, ya que no cesó de aumentar el peso económico del Estado y su participación en la administración de la renta nacional, y esto no sólo en los países integrados a su órbita. Pero en la segunda mitad de la centuria se invirtió la tendencia, sobre todo a partir de 1989, año de la "volteada" (Rodríguez Kauth, 1994) del Muro de Berlín y del desastre del socialismo real. Si la derecha actual se caracteriza por postular menos Estado, es obvio que está triunfando a escala universal y que el punto medio de la tensión política se desplaza hacia las privatizaciones, o sea, hacia la derecha.

No debe olvidarse durante el debate acerca del Estado — que a veces llega a la pretensión de su desaparición- la clásica definición que sobre el mismo ofreció M. Weber (1944) cuando dijo que es aquella comunidad humana que dentro de un territorio aspira con éxito al monopolio legítimo de la violencia. Lo cual supone el condicionamiento de las acciones de quienes habitan su espacio con reglas fijadas por él. En definitiva, el Estado es la articulación de un conjunto de normas y la posibilidad de usar la fuerza para obligar a su cumplimiento.

Esta derechización, empíricamente verificable, no significa ni la anárquica negación del Estado que estamos sufriendo en Argentina, ni el rechazo de toda intervención soberana en la vida económica; sólo revela una tendencia con infinidad de posiciones intermedias, y sin duda, reversible. Una distinción tan dinámica, inestable y versátil como ha sido la de la derecha y la de la izquierda políticas hace pretencioso suponer que se ha llegado a un planteamiento definitivo.

La tensión entre mercantilismo y librecambismo es antigua; pero, en los finales de la segunda mitad del siglo XX, el fracaso del socialismo real decidió la alternativa a favor de la iniciativa privada y del libre mercado por parte de grandes masas de electores que han volcado su decisión en esa dirección. Esta es la razón de que los izquierdismos supervivientes, como la llamada socialdemocracia, no cesen de aproximarse a los programas derechistas que se concretan en liberalismo ("neo" o "paleo"), desregulación y privatización, o sea, amortización de los efectos del moderno izquierdismo intervencionista, inspirado principalmente en Marx y en Keynes. 
El izquierdismo estatista se ha quedado sin pensadores y va a remolque de los liberales económicos que han contado con figuras como las de Hayek o Friedman. Los teóricos del izquierdismo han pasado a la erudición o al olvido y, los que se reciclan de neoliberales ocasionales, han dejado de ser intelectual y moralmente respetables en la medida en que pretendan aleccionar desde el oportunismo coyuntural.

La regla de más o menos Estado es independiente de las razones teóricas o prácticas que conduzcan a fijar posiciones concretas. Dado que toda actitud política es moral y entraña una jerarquización de valores, la regla propuesta, en sí misma, es éticamente neutra, puesto que permite situar sin exaltar ni condenar. Existe un segmento, uno de cuyos extremos está ocupado por el totalitarismo (todo en el Estado, nada fuera de él). El otro extremo sería el de supresión del Estado. El carácter continuo de esta línea permite infinitas posibilidades, recíprocamente relativas. Es un criterio geométrico, amplísimo y sin implicaciones axiológicas intrínsecas. La localización clarificadora no supone juicio alguno de valor, salvo el universal e insoslayable de todo conocimiento científico que es la veracidad. El que propugna menos Estado se coloca a la derecha del otro.

¿Qué paralelismo existe entre más o menos Estado y más o menos mercado? No es la misma contraposición con nombres distintos porque el libre mercado ha de ser garantizado por el Estado frente a los monopolios y otras corruptelas. El mercado libérrimo no coincide con la supresión del Estado, sino con su minimización. Es cierto que más Estado implica más intervención en la sociedad y en la economía, mientras que menos Estado supone menos intervención. En general, a medida que se avanza hacia la izquierda del segmento, se incrementan el volumen y la intensidad de la intervención.

En el presente panorama politológico no se divisa una regla más aséptica, general y circunstancialmente útil para clasificar a las corrientes políticas que la de más o menos Estado.

\section{Conclusiones}

Las nociones de izquierda y derecha son relativas y -aplicadas en política- sus contenidos han cambiado, incluso polarmente. Los centros son aún más incicrtos y movedizos. Los tres sólo pueden ser caracterizados en un tiempo y un espacio.

A las actuales corrientes políticas, sean cuales fueren sus nombres of iciales, sus seudónimos, o denominaciones subliminales, se las sitúa en la línea sustantiva averiguando si propugnan más o menos Estado que sus rivales en lucha por orientar o conquistar el poder. La que aspire a "menos" (privatizaciones y desiregulaciones) se localiza a la derecha de las otras. Esa es la clave del acertijo que hoy se enmascara bajo las retóricas publicitarias. 
Lo demás resulta políticamente secundario $y$, de allí, la general anemia intelectual y ética de la clase gobernante.

\section{Bibliografia}

Del Río, E.: (1999) La Izquierda. Trayectoria en la Europa Occidental. Ed. Talasa, Madrid.

Falcon, M. I.: "El Psicoanálisis y lo siniestro". Revista Intercontinental de Psicoanálisis Contemporáneo, (México), Vol. 2, No 1, 1997.

Ferrater Mora, J.: Diccionario de Filosofia. Editorial Sudamericana, Bs. Aires, 1971.

Fukuyama, F.: “'El fin de la historia?". Revista Babel, Buenos Aires, N 14, 1990.

Hobbes, Th.: (1651) Leviatán. Ed. Nacional, Madrid, 1979.

Marx, C.: (1847) Miseria de la Filosofia. Ed. El Quijote, Bs. Aires, 1946.

Marx, C.: (1847) La Ideología alemana. Editorial Pueblos Unidos, Montevideo, 1958.

Rodríguez Kauth, A.: Psicología de la Hipocresía. Ed. Almagesto, Bs. Aires, 1993.

Smith, A.: (1784) La Riqueza de las Naciones. Alianza Editorial, Madrid, 1994.

Schmitt, C.: (1932) El Concepto de lo Político. Ed. Folios, Bs. Aires, 1985. 